\title{
Study of design parameters for squeeze film air journal bearing - excitation frequency and amplitude
}

\author{
C. Wang and Y. H. J. Au \\ Advanced Manufacturing and Enterprise Engineering, School of Engineering and Design, Brunel Univ., UK
}

Received: 15 February 2011 - Revised: 17 May 2011 - Accepted: 4 July 2011 - Published: 26 July 2011

\begin{abstract}
The paper presents a design of squeeze film air journal bearing based on the design rules derived from CFX and FEA simulation study of an air film in between two flat plates, one of which was driven in a sinusoidal manner. The rules are that the oscillation frequency should be at least $15 \mathrm{kHz}$ and that the oscillation amplitude be as large as possible to ensure a greater film thickness and to allow the bearing to reach its stable equilibrium quickly. The proposed journal bearing is made from AL2024-T3, of $20.02 \mathrm{~mm}$ outer diameter, $600 \mathrm{~mm}$ length and $2 \mathrm{~mm}$ thickness. Three $20-\mathrm{mm}$ long fins are on the outer surface of the bearing tube and are spaced $120^{\circ}$ apart; three longitudinal flats are milled equi-spaced between the fins and two piezoelectric actuators are mounted lengthwise on each flat. Such a design produces a modal shape on the bearing tube which resembles a triangle. When excited in this mode at the frequency of $16.37 \mathrm{kHz}$, and a voltage of $75 \mathrm{~V} \mathrm{AC}$ with $75 \mathrm{~V} \mathrm{DC}$ offset acting on the piezoelectric actuators, the air gap underneath of the bearing tube behaves as a squeeze air film with a response amplitude of $3.22 \mu \mathrm{m}$. The three design rules were validated by experiments.
\end{abstract}

\section{Introduction}

Precision engineering dictates that bearings used in machine tools must be capable of producing high precision motion with low friction and wear and generating very little heat in an oil-free condition (Stolarski and Chai, 2006b). Whilst aerostatic and aero-dynamic bearings can meet these requirements, they do come with bulky ancillary equipment, such as air compressors and hoses, and hence not very portable. A search for better bearings was an activity that has exercised the minds of many researchers.

To study the bearing behaviour of a thin air film between two surfaces, the Reynolds equation is used. Stolarski and Chai (2006a) identified three mechanisms from the equation that would show a pressure-generating phenomenon, which gives the bearing its load-carrying capability. The first refers to the "physical wedge" as is found in hydrodynamic bearings where the fluid flows through a wedge; the second requires the two surfaces to contract or expand in-plane in order to create a variable velocity on the bearing surfaces; the third requires that the two bearing surfaces move normal to

Correspondence to: Y. H. J. Au

(joe.au@brunel.ac.uk) each other with an oscillating velocity and is known as the "squeeze film" effect. Stolarski and Chai (2006a) asserted that the pressure generated by the hydrodynamic and squeeze film effects is of a similar order of magnitude and hence the justification for exploring the latter in the design of a new type of bearing. Squeeze film bearings have the significant advantage due to the fact that they do not require air compressors and connecting hoses; the equipment needed for generating the squeeze film action is far smaller and it can be miniaturised to the extent that it becomes a single package with the bearing.

In the design investigated by Stolarski and Woolliscroft (2007) and Yoshimoto et al. (1995), the squeeze film air bearings, made from Aluminium, used elastic hinges to ensure easy flexing of the bearing plates when driven at and around the fundamental frequency of a few $\mathrm{KHz}$ by stack piezoelectric actuators. The presence of the elastic hinges helps increase the dynamic response resulting in a thicker air film but because of the intricate machining required, the manufacturing cost increased. In addition, the driving frequency, being of a few $\mathrm{kHz}$, is within the sensitive audible range, which can cause annoyance. Yoshimoto et al. (2006) and Ono et al. (2009) proposed another design of bearing that was driven at ultrasonic frequency with single-layer piezoelectric actuators to avoid problem of audible noise during operation. The 
use of the single-layer piezoelectric actuators can reduce the power consumed.

The purposes of work reported in this paper are:

1. To develop a model that affirms the existence of positive pressure developed in a squeeze-film air bearing;

2. To develop a finite-element model for a single layer piezoelectric actuator that uses realistic boundary conditions;

3. To design a journal squeeze film air bearing using the design rules derived from the modelling of the squeeze air film.

In the rest of this paper, Sect. 2 presents a theory of the squeeze air film for flat plates, proving the existence of asymmetrical pressure that produces a levitation force. Section 3 considers the design rules of a squeeze film bearing leading to the design of a journal bearing, which was subsequently tested to establish its dynamic characteristics. Section 4 deals with the discussion of the simulation and experimental results. Finally, Sect. 5 gives the conclusion.

\section{Theory of squeeze air film for flat plates}

\subsection{Pressure profile}

Consider an air film that is squeezed between two flat plates having relative sinusoidal motion of frequency $\omega$ at amplitude $e$, in the direction of the film thickness, as shown in Fig. 1a. The pressure at a point in the air film is governed by the Reynolds equation,

$\frac{\partial}{\partial \mathrm{X}}\left(H^{3} p \frac{\partial p}{\partial \mathrm{X}}\right)+\frac{\partial}{\partial \mathrm{Z}}\left(H^{3} p \frac{\partial p}{\partial \mathrm{Z}}\right)=2 \sigma \frac{(\partial P H)}{\partial \tau}$

Equation (1) is given in a non-dimensional form (Stolarski, 2009). $X, Y$ and $Z$ are the coordinates of a point in the air film expressed as a fraction of its length, width and thickness respectively; $P=\frac{p}{p_{0}}$ is the ratio of the instantaneous pressure to the initial pressure; $H$ the ratio of the instantaneous to the initial film thickness; $\sigma$ the squeeze number; and $\tau=\omega t$ the non-dimensional time obtained as the product of the angular frequency of oscillation $\omega$ and time $t$.

The squeeze number is defined as $\sigma=\frac{12 \mu \omega L^{2}}{p_{0} h_{0}^{2}}$ where $\mu$ is the dynamic viscosity and $L$ the length of the air film.

The instantaneous film thickness $h=h_{0}+e \sin (\tau)$ and hence the instantaneous film thickness ratio, being $h / h_{0}$ is given by $H=1+\varepsilon \sin (\tau)$.

\subsection{Equation of motion of flat plates}

If now the bottom plate is given a sinusoidal motion normal to its surface while the top plate is supported by the air film,

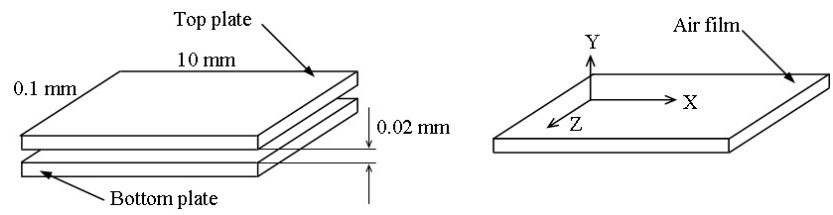

Figure 1. (a) Dimensions of the plates and the air film thickness; and (b) the air film in the rectangular coordinate system used.

the top plate will be caused to move in a manner governed by the Newton's Second Law, namely

$m \frac{d v}{d t}=F_{\mathrm{L}}-m g$

In Eq. (2), $m$ and $v$ are the respective mass and velocity of the top plate, $F_{\mathrm{L}}$ is the levitation force exerted by the air film and $m g$ is the weight force of the top plate.

Equation (1) computes the pressure profile of the air film between the two plates. From the pressure profile is obtained the force of levitation $F_{\mathrm{L}}$. The corresponding value of velocity $v$ can then be found from Eq. (2), from which the displacement of the top plate is calculated by integration. This displacement, together with the sinusoidal motion of the bottom plate, changes the air film thickness $h$ and hence the thickness ratio $H$. This, in turn changes the pressure profile as computed from Eq. (1). By repeating the afore-mentioned calculation procedure over time, it is possible to determine the corresponding displacement response of the top plate.

\subsection{Simple model of oscillating plates and boundary conditions}

The simple model considered is the one as shown in Fig. 1a, with dimensions of the plates and the initial air film thickness as indicated. The bottom plate was given a sinusoidal motion whilst the top plate, of mass $6.24 \times 10^{-3} \mathrm{~kg}$, responded also with a sinusoidal motion. The air film, as shown in Fig. 1b, is assumed to have no leakage around the three sides of its edges, namely the left, front and back sides; but there is leakage from the right side. Such assumptions are justified by the following considerations:

1. The left side is on the plane of symmetry of the complete air film. In other words, what is shown in Fig. 1b is only the right half and hence there is no sideway flow of air across the symmetry plane.

2. The front and back sides do not have air flow across them because of the symmetrical arrangement of the three pairs of bearing plates in the proposed journal bearing design - see Fig. 13 - and the synchronised driving of them.

3. The right side, however, is exposed to the atmosphere and leakage is expected. 


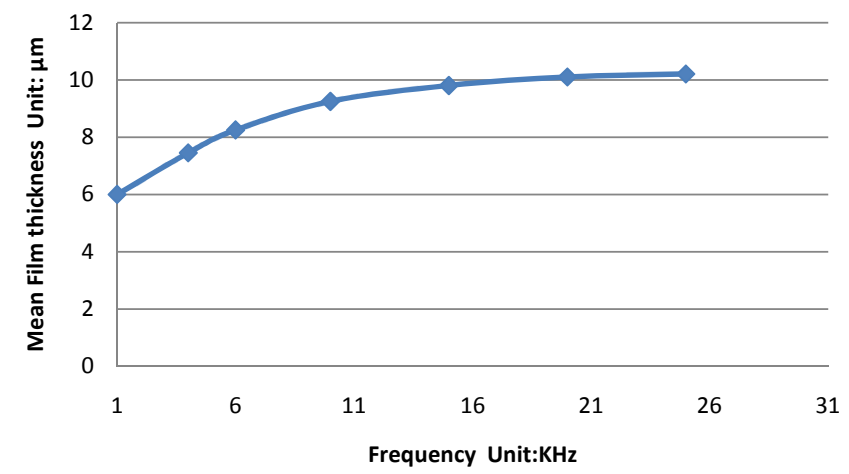

Figure 2. Mean air film thicknesses versus excitation frequency of bottom plate.

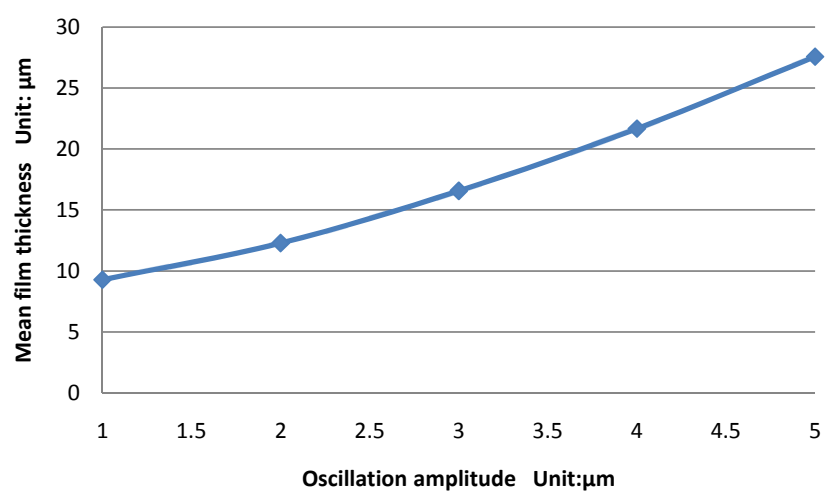

Figure 3. Mean film thickness versus oscillation amplitude of bottom plate (oscillation frequency at $10 \mathrm{kHz}$ ).

The computation was performed with CFX (Guo et al., 2005) instead of home-built programming codes (Stolarski and Woolliscroft, 2007) to save time.

\subsection{Calculation results}

Figure 2 shows the relationship between the air film thickness and the oscillation frequency of the bottom plate. It is observed that the mean air film thickness at first increases with oscillation frequency but it reaches a constant value beyond around $15 \mathrm{kHz}$.

Figure 3 shows the relationship between the mean air film thickness and the oscillation amplitude with the oscillation frequency of the bottom plate kept at $10 \mathrm{KHz}$. It is noted that as the oscillation amplitude increases the mean air film thickness increases in an exponential fashion.

Figure 4 shows the steady-state pressure distribution of the air film over a period of oscillation along the $\mathrm{x}$-axis (Fig. 2b) from the left edge $(x=0 \mathrm{~mm})$ to the right edge $(x=10 \mathrm{~mm})$ where the air film interfaces with the atmosphere whose pressure ratio $P$ is 1 . There are 9 pressure profile curves shown and they represent the pressure at different time instants in

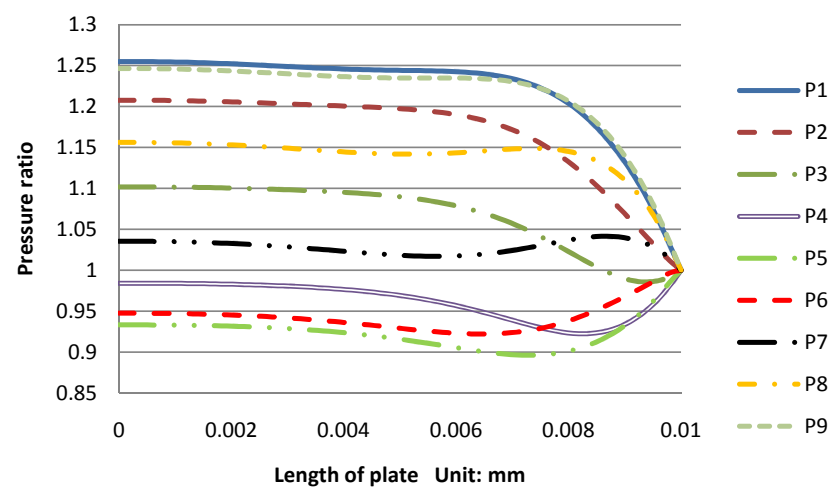

Figure 4. Steady-state pressure distribution in the $\mathrm{x}$-direction (Fig. 2b) of air film in a period of oscillation of bottom plate in frequency of $10 \mathrm{KHz}$.

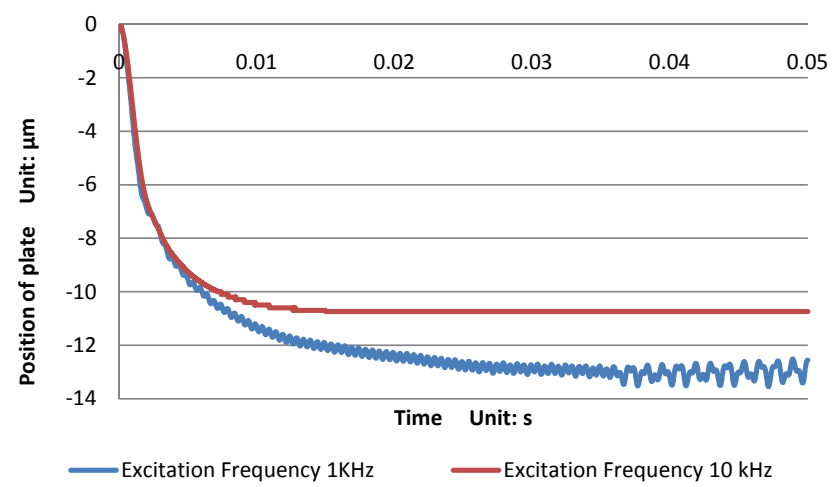

Figure 5. Transition to equilibrium position of top plate for two excitation frequencies of bottom plate at $1 \mathrm{kHz}$ and $10 \mathrm{kHz}$.

the cycle of oscillation such that the time interval between successive points, for example $\mathrm{P} 1$ and $\mathrm{P} 2$, is constant, being $12.5 \mu \mathrm{s}$. It is noted that the mean pressure ratio in the film at any distance is above unity; thus an up-thrust is created to levitate the top plate. The same conclusion was drawn by the authors in their paper using the theory of ideal gas law (Wang and $\mathrm{Au}, 2011$ ).

Figure 5 shows the transition to the final equilibrium position of the top plate from the initial film thickness of $20 \mu \mathrm{m}$ at the two oscillation frequencies of the bottom plate, namely $1 \mathrm{kHz}$ and $10 \mathrm{kHz}$. The observation from Fig. 3 that the mean film thickness increases with oscillation frequency below $15 \mathrm{kHz}$ is seen also to hold true here. In addition, at higher oscillation frequency of the bottom plate the response of the top plate shows greater stability, with no residual oscillation, achieved at around $0.037 \mathrm{~s}$. 


\section{Design of the proposed squeeze film air bearing}

Figures 2, 3 and 5 highlight some rules for the design of squeeze air film bearings. Specifically:

1. According to Fig. 2, to ensure a greater film thickness, the oscillation frequency imposed on the air film should be high, preferably above $15 \mathrm{kHz}$ because the end leakage becomes insignificant.

2. Figure 3 points to the fact that the greater the oscillation amplitude of the air film, the greater is its mean thickness.

3. Figure 5 suggests that with a greater oscillation frequency of the air film, the bearing reaches its stable equilibrium position much more quickly.

Using these three design rules, a design of the squeeze film air journal bearing (Ha et al., 2005; Zhao and Wallaschek, 2009), as shown in Fig. 13, is proposed. This bearing is in the shape of a hollow round tube with three longitudinal flats milled equi-spaced around the circumference. Two piezoelectric actuators are mounted length-wise on each flat and they are driven simultaneously by an AC voltage with a DC offset. The material and geometry of the tube are such chosen that at least one modal frequency exists which is above $15 \mathrm{kHz}$ and has a desirable modal shape.

With such a design, the $\mathrm{x}$-axis (Fig. 1b) of the bearing plate is aligned with the longitudinal axis of the bearing tube, the $y$-axis with the radial axis, and the z-axis with the tangential axis to the circumference. Since the film thickness is very small in relation to the width or length of the bearing, the bearing plate can be assumed to be flat. Leakage is only significant in the longitudinal directions (both positive and negative directions of the $\mathrm{x}$-axis) but otherwise virtually nonexistent in the radial (y-axis) or tangential (z-axis) direction. To first approximation the model presented in Sect. 2 holds.

The modal shape of choice should be one that produces purely a radial deformation of the tube wall without the tube experiencing any torsion. Therefore the only possible modal shape for the design as shown in Fig. 13 has to be a triangle similar to Fig. 14. To encourage the tube to distort into a triangle, three external fins are added, which in effect partitions the tube into three $120^{\circ}$ sectors. The fins do not cover the whole length of the tube but are foreshortened. This is to make sure that both ends of the tube do not deform or at least not as much as the inner sections of the tube; consequently the end leakage in the longitudinal direction can be further minimised.

At the desired mode as described above, the three fins can be imagined to have only radial motion and the tube wall between any consecutive pair of fins flexes about the fins as its end supports. Its static and dynamic behaviour is modelled in the next section.

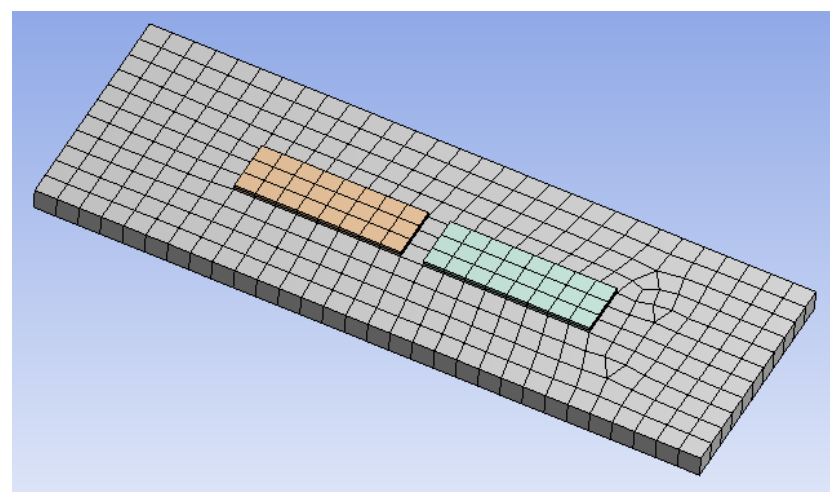

Figure 6. Model of rectangular plate with two single-layer piezoelectric actuators mounted on top surface.

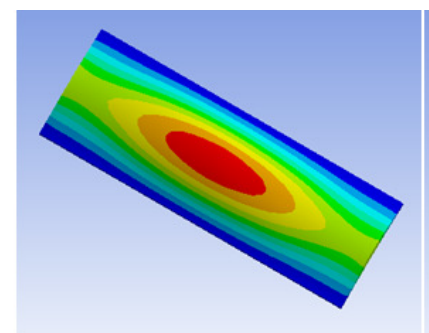

(a) Mode shape $1(23606 \mathrm{~Hz})$

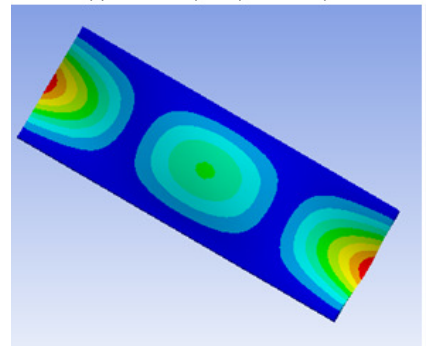

(c) Mode shape $3(26600 \mathrm{~Hz})$

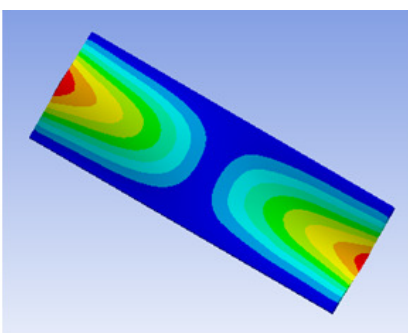

(b) Mode shape $2(24864 \mathrm{~Hz})$

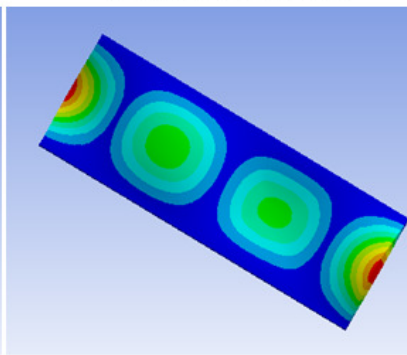

(d) Mode shape $4(30112 \mathrm{~Hz})$
Figure 7. Mode shapes and natural frequencies of rectangular plate; colour red indicates maximum deformation and colour blue, no deformation.

\subsection{Modal analysis}

Figure 6 shows a flat plate with a width of $21 \mathrm{~mm}$ (equal to the circumferential width of the tube between two consecutive fins), length of $60 \mathrm{~mm}$ (the length of the tube) and thickness of $2 \mathrm{~mm}$ (the thickness of the tube). The plate has a built-in support along the two $60-\mathrm{mm}$ edges. Two singlelayer piezoelectric actuators are mounted on the top surface of the plate as a driving unit; the dimensions of the singlelayer piezoelectric actuator are $15 \mathrm{~mm} \times 5 \mathrm{~mm} \times 0.5 \mathrm{~mm}$.

Using ANSYS Workbench, a modal analysis was performed on the flat rectangular plate. The first four natural frequencies and the corresponding mode shapes are as shown in Fig. 7. Mode shape 1, obtained by exciting the two singlelayer piezoelectric actuators at $23606 \mathrm{~Hz}$ (Yoshimoto et al., 


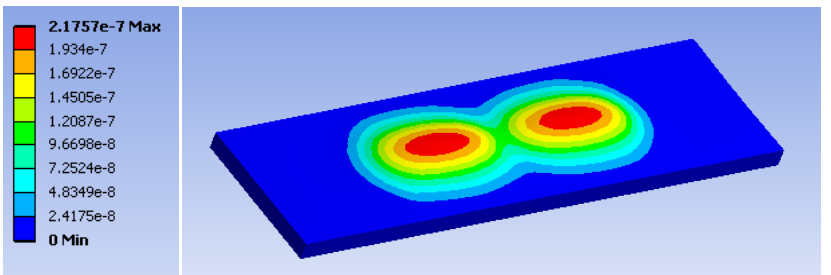

Figure 8. Static deformation of rectangular plate when a 150 V DC was applied to the two actuators.

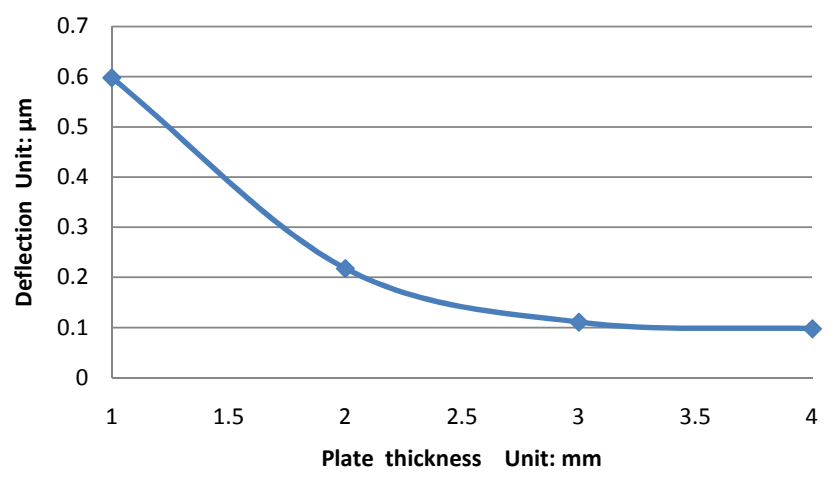

Figure 9. Relationship between maximum static deformation and plate thickness.

2006), gives the most desirable mode shape feature. This is because the maximum deformation region occurs right at the centre of the plate, resulting in minimum leakage at the two opposite 21-mm edges. In addition, the excitation frequency, being higher than $15 \mathrm{kHz}$, is also conducive to reducing end leakage according to Fig. 2.

\subsection{Static analysis}

When a DC voltage is applied to two single-layer piezoelectric actuators mounted on the rectangular plate, a static deformation results. A larger deformation is preferred to a smaller one because of the thicker squeeze air film that it creates. Evidently the deformation is a function of the plate thickness.

Figure 8 shows the static deformation that appears on the rectangular plate when a $150 \mathrm{VDC}$ was applied to the piezoelectric actuators with $0 \mathrm{~V}$ and $150 \mathrm{~V}$ on the respective bottom and top surfaces. A maximum deformation of $0.21757 \mu \mathrm{m}$ is seen to occur at two regions, as shown in red in Fig. 8, symmetrically disposed from the centre line parallel to the short sides of the plate.

The relationship between the thickness of the plate and the deformation is shown in the Fig. 9. It is observed that the plate deflection increases disproportionately as the plate thickness decreases. The static deformation of a 1-mm thick plate is about 3 times as big as that of 2-mm thickness; however, as thickness increases from 3 to $4 \mathrm{~mm}$, the static deformation hardly changes, being around $0.1 \mu \mathrm{m}$.

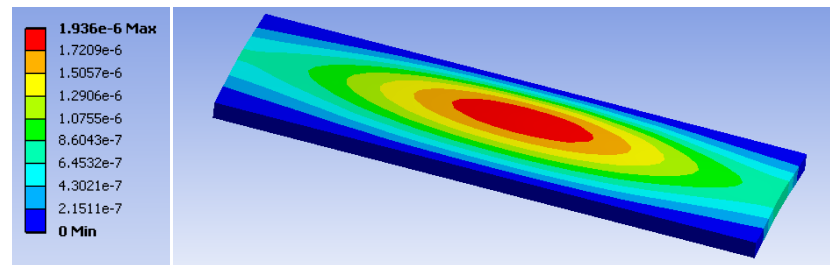

Figure 10. Dynamic response of plate when driven at the fundamental natural frequency of $23606 \mathrm{~Hz}$.

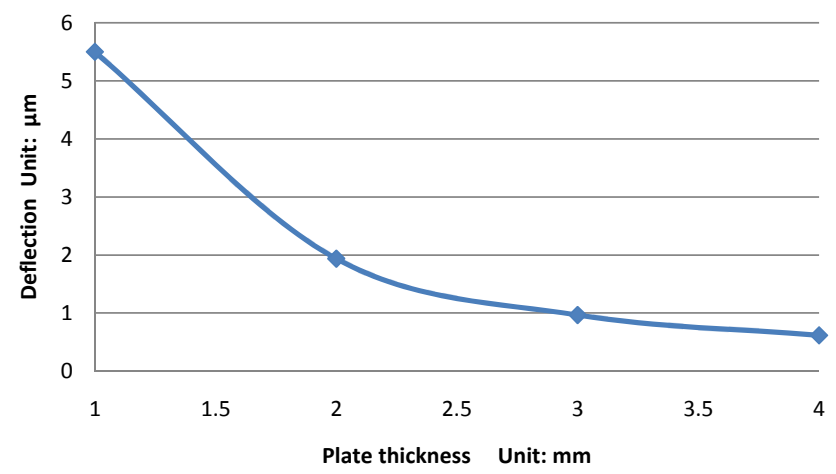

Figure 11. Dynamic deformation versus plate thickness when excited at natural frequency of plate.

\subsection{Dynamic analysis}

Dynamic analysis is used to determine the dynamic response of a structure under a sinusoidal excitation force. The excitation force in this case is created from the alternate expansion and compression of the piezoelectric actuators when they are driven by an $\mathrm{AC}$ voltage at $75 \mathrm{~V}$ on top of a DC offset also at $75 \mathrm{~V}$. To take advantage of the mechanical gain at resonance, the excitation frequency was chosen to coincide with the Mode 1 frequency of $23606 \mathrm{~Hz}$, as identified in Sect. 3.1, in order to achieve maximum dynamic response, thus giving a better floating performance as suggested by Fig. 3 .

Figure 10 shows the dynamic response of the rectangular plate when excited at $23606 \mathrm{~Hz}$ with the AC $75 \mathrm{~V}$ and the DC offset $75 \mathrm{~V}$ as occurring at the central region (shown in red) where the amplitude is $1.936 \mu \mathrm{m}$ (Yoshimoto et al., 2006) . As expected the response of the plate is of the same shape as mode shape 1 . By varying the beam thickness from 1 to $4 \mathrm{~mm}$, the maximum amplitude of response is seen to decrease in an exponential manner as shown in Fig. 11, similar to that observed in the static analysis (Fig. 9). A comparison between the two analyses is presented in Fig.12: the difference in magnitude is striking; for a 2-mm thick plate, the dynamic deformation is about 9 times as large as the static deformation.

If maximum dynamic deformation was the only design criterion, then the thinner the plate the better. But the modal frequency drops as the plate thick decreases. Thus, for example, 


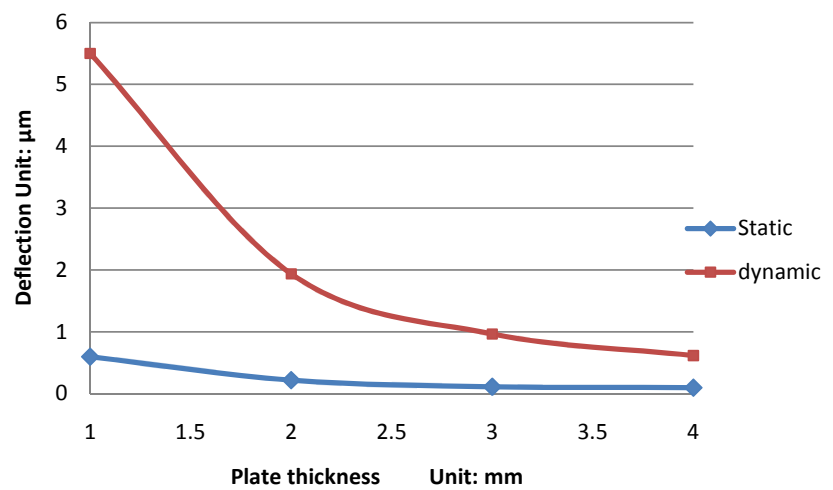

Figure 12. Comparison between static and dynamic plate deformations.

the 1-mm thick plate has a mode 1 frequency of $11.835 \mathrm{kHz}$, which is well below the threshold frequency of $15 \mathrm{kHz}$, thus creating substantial end leakage (Fig. 2) and a long transition time to equilibrium (Fig. 5); furthermore the resulting strain in the driving piezoelectric actuators may be too high to cause them to fracture.

\subsection{Experimental results for the designed squeeze film air journal bearing}

Based on the results of the static and dynamic analyses and of the three design rules formulated in Sect. 3, the final design is created, which is as shown in Fig. 13. The journal bearing is made from the material AL2024-T3, and has a diameter of $20.02 \mathrm{~mm}$, a length of $60 \mathrm{~mm}$ and a thickness of $2 \mathrm{~mm}$. Three fins, each $20 \mathrm{~mm}$ long, are positioned $120^{\circ}$ apart on the outer circumference of the bearing tube; they are designed to provide a desirable modal shape of a triangular cross-section when excited by the actuators. This enables the air gap underneath the actuators to behave effectively as a squeeze air film. The round bar has a diameter of $19.99 \mathrm{~mm}$ and the surface was produced by cylindrical grinding.

From the FEA modal modelling, the Mode 13 was identified to have the desired deformed geometry of a triangle and it has the modal frequency of $16.37 \mathrm{kHz}$, which is above the $15 \mathrm{kHz}$ threshold. The corresponding mode shape is as shown in Fig. 14 where the red end of the colour spectrum denotes greater deformation. It can be observed that the outer edges of the round sleeve do not appear to deform much while the middle section deforms noticeably.

\subsubsection{Experimental set up}

Figure 15 shows the set up of equipment for the dynamic response experiment. The following items of equipment were used:

1. A signal generator -0 to $5 \mathrm{~V}$ and 0 to $100 \mathrm{kHz}$ (S J Electronics)

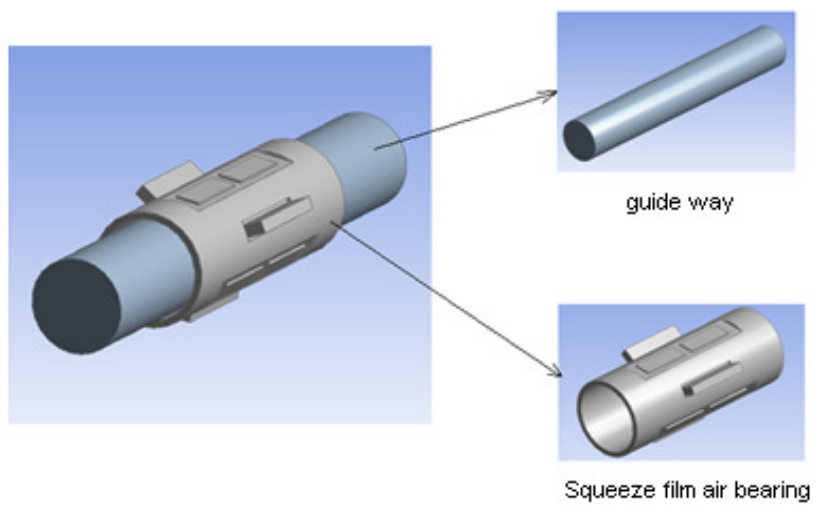

Figure 13. Squeeze film air journal bearing with six single-layer piezoelectric actuators mounted on three milled flat surfaces, shown with the guide way in the shape of a round bar.

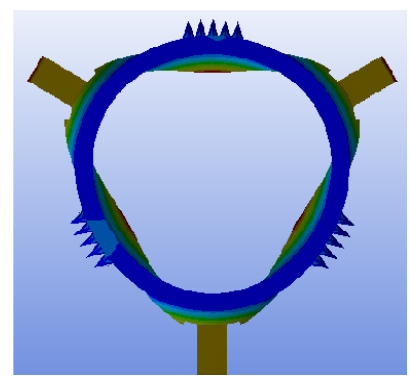

Figure 14. Mode shape 13 of squeeze film air journal bearing (not to scale).

2. An actuator driver - ENP-1-1U (Echo Electronics)

3. An actuator driver monitor - ENP-50U (Echo Electronics)

4. A capacitance displacement sensor and a gauging module - MicroSense 5810; measurement bandwidth up to $100 \mathrm{kHz}$; measurement ranges $\pm 100 \mu \mathrm{m}$; accuracy $\pm 49.69 \mathrm{~nm}$ and resolution $22.3 \mathrm{~nm}$ (Ixthus)

\section{A data acquisition card - PXI 6110 (National Instruments)}

The signal generator created a sinusoidal wave which was amplified by the actuator driver and shaped by the actuator monitor to provide an excitation signal, with a $75 \mathrm{~V} \mathrm{DC}$ offset and a $75 \mathrm{~V}$ peak-to-zero AC sinusoid. This excitation signal was used to drive the single layer piezoelectric actuators. The vibration response of the structure caused by the actuators was measured by the capacitance displacement sensor, whose output was sampled into a PC via the data acquisition card driven by a LabVIEW program. 


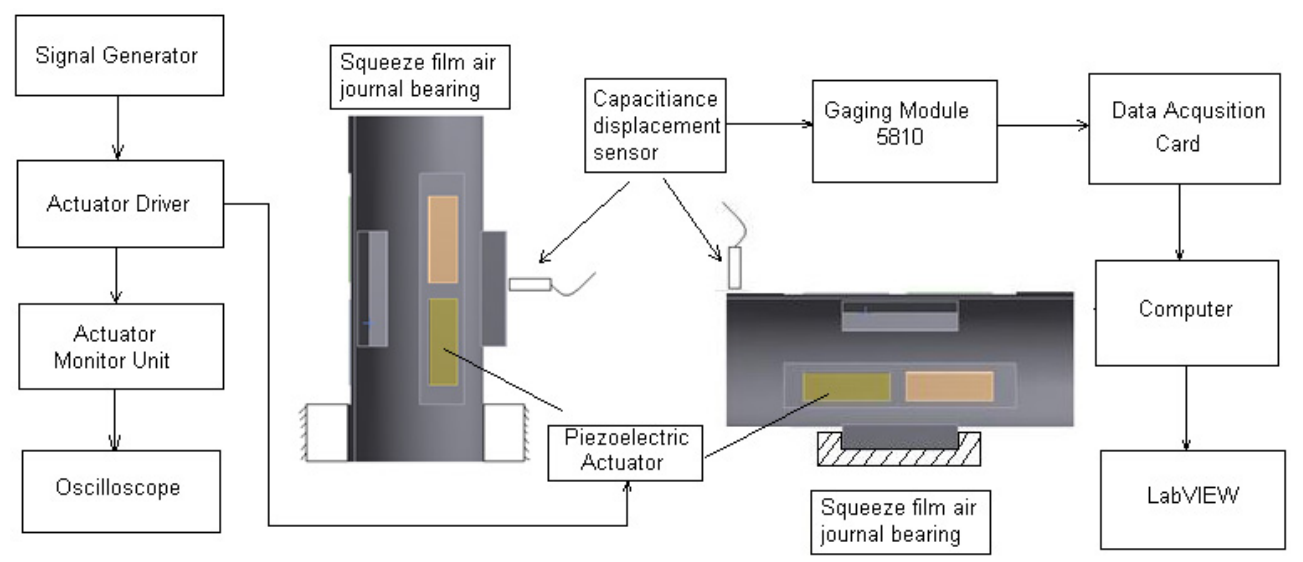

Figure 15. Schematic diagram of the experimental set-up.

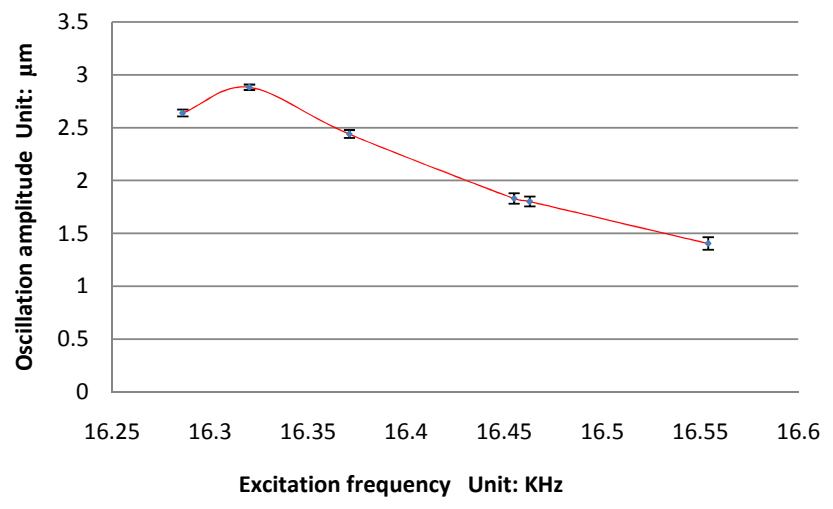

Figure 16. Oscillation amplitude at the centre of the bearing shell at Mode 13 versus excitation frequency at $75 \mathrm{~V}$ AC input with 75 V DC coupling; error bars represent \pm 2 standard errors.

\subsubsection{Oscillation amplitude on vibrating shell of journal bearing and excitation frequency}

The maximum amplitude of oscillation at the vibrating shell of the bearing was measured within a range of frequencies, $16.28 \mathrm{kHz}$ to $16.55 \mathrm{kHz}$, in the vicinity of the predicted Mode 13 frequency of $16.37 \mathrm{~Hz}$. The results are as shown in Fig. 16. The measurements were made 10 times and it is the average that is shown on the graph; the corresponding error bar represents \pm 2 standard errors. The narrow extent of the error bars suggests good measurement repeatability and high precision of the displacement amplitude obtained. From Fig. 16, it is observed that the natural frequency for Mode 13 was $16.32 \mathrm{kHz}$; and that the amplitude of oscillation was $2.88 \mu \mathrm{m}$, compared to the simulated result of $3.22 \mu \mathrm{m}$ from ANSYS Workbench modelling.

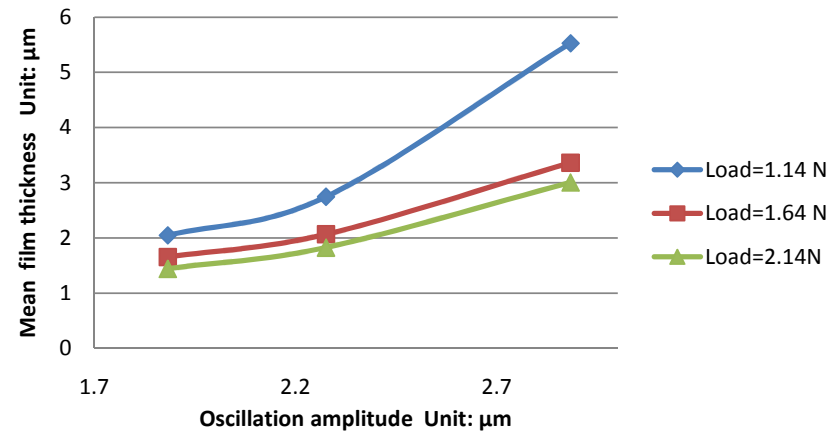

Figure 17. Mean film thickness versus oscillation amplitude at three load levels.

\subsubsection{Mean film thickness and oscillation amplitude}

According to the second design rule the mean squeeze film thickness increases with the amplitude of oscillation of the shell. Experiments were conducted to validate this assertion. Figure 17 shows the relationship between the mean film thickness and the oscillation amplitude at three load levels. The loading was implemented by attaching a weight to the journal bearing and three loads were studied, namely $1.14 \mathrm{~N}$, $1.64 \mathrm{~N}$ and $2.14 \mathrm{~N}$. These loads were hung on the bottom fin see Fig. 14 - such that there was a squeeze air film at the top and another pair symmetrically disposed at $120 \circ$ on either side. In Fig. 17, it can be seen that the mean film thickness increases in an exponential fashion with increasing oscillation amplitude for all three different loads.

\subsubsection{Comparison between experimental and theoretical mean film thicknesses}

With the journal bearing loaded as described in Sect. 3.4.3 corresponding to the orientation of the three squeeze films as shown in Fig. 14, an approximate simulation CFX model 
Table 1. Comparison between flat plate and curved shell in respect of dynamic response.

\begin{tabular}{lcc}
\hline & $\begin{array}{c}\text { Flat Rectangular Plate } \\
2 \mathrm{~mm} \text { thick }\end{array}$ & $\begin{array}{c}\text { Tubular Bearing with Curved Shell } \\
2 \mathrm{~mm} \text { thick }\end{array}$ \\
\hline Natural frequency & $23606 \mathrm{~Hz}$ & $16368 \mathrm{~Hz}$ \\
Dynamic deformation & $1.99 \mu \mathrm{m}$ & $3.22 \mu \mathrm{m}$ \\
\hline
\end{tabular}

was formulated and analysed. Two simplifying assumptions were made:

1. As the surrounding sleeve is loaded, the squeeze film at the top has a thickness which is much smaller than that at the other two squeeze film situated towards the bottom (Fig. 14), such that the levitation force created is solely due to the top squeeze film;

2. The top squeeze film is flat and there is no leakage when in operation; and

3. The upper plate of the top squeeze film translates bodily up and down with no deformation.

The CFX simulation modelled an air film which was $30 \mathrm{~mm}$ long, $0.1 \mathrm{~mm}$ wide and $0.03 \mu \mathrm{m}$ thick using the same set of boundary conditions as that described in Sect. 2.3. Since the bearing shell of the top squeeze film did not oscillate as a rigid body but rather flexed itself at the Mode 13 natural frequency, the average amplitude of oscillation of $1.31 \mu \mathrm{m}$ was used in the simulation. This average was obtained by measuring the modal shape of the bearing shell at the top squeeze film with the bearing driven at the Mode 13 natural frequency of $16.32 \mathrm{kHz}$ and then taking an arithmetical average from these measurements.

Figure 18 shows the results from the simulation as compared to those obtained from the experiment for different loadings. There is broad agreement between the two in terms of the trend and of the values of the mean film thickness, with better fit towards the higher loading. It is surmised that the better fit could be due to the fact that the first assumption becomes more correct as the loading increases; further work needs to be done in this area. The agreement between the theoretical and experimental results serves, in some way, to validate the simulation results in Sect. 2 , from which the three design rules were derived.

\section{Discussions}

In this paper the flat rectangular plate was first studied in order to identify important design rules and parameters that would better inform subsequent design activity, leading to the design of a tubular bearing with fins. A comparison between the dynamic simulation results obtained from the flat plate and the curved shell is informative; Table 1 summarises the effort.

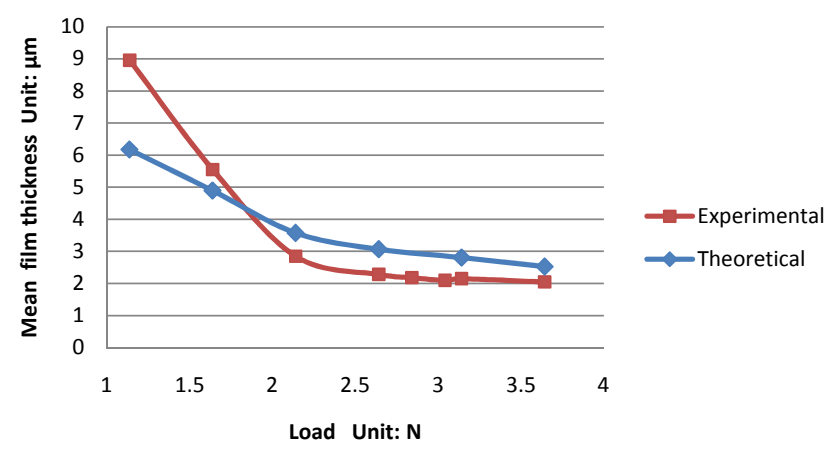

Figure 18. Comparison of theoretical and experimental for mean film thickness.

The flat plate is seen to have a higher natural frequency than the curved counterpart. This is due to two reasons: (1) the flat plate was subjected to a more severe end-fixing condition, namely built-in fixing along the full length, compared to the partial fixing via the foreshortened fins, which themselves are free to move radially, on the curved shell; (2) the curved shell has a milled flat for the actuators, which reduces the shell's stiffness in bending locally.

The foreshortened fins can be responsible for the larger dynamic response at $3.22 \mu \mathrm{m}$ compared to the $1.99 \mu \mathrm{m}$ on the severely edge-constrained plate.

\section{Conclusions}

Three design rules for squeeze air film bearings were produced and verified from the research:

1. To ensure a greater film thickness and to reduce end leakage, the oscillation frequency imposed on the air film should be high, preferably above $15 \mathrm{kHz}$ (Fig. 2).

2. The greater the oscillation amplitude of the air film, the greater is its mean thickness (Fig. 3).

3. With a greater oscillation frequency of the air film, the bearing reaches its stable equilibrium position much more quickly (Fig. 5).

Based on the design rules, a journal squeeze air film bearing was designed (Figs. 13 and 14) and analysed. The bearing was designed to be driven at its 13th mode at the frequency of $16.37 \mathrm{kHz}$ at which the amplitude response was $3.22 \mu \mathrm{m}$ 
and the modal shape produced a squeezing action on the air film between the journal shell and the bearing shaft.

These three design rules were validated from experiments conducted on the journal squeeze air film bearing, as demonstrated in Figs. 17 and 18.

Edited by: A. Barari

Reviewed by: T. Stolarski and another anonymous referee

\section{References}

Guo, Z. L., Hirano, T., and Kirk, R. G.: Application of CFD analysis for rotating machinery - Part 1: Hydrodynamic, hydrostatic bearings and squeeze film damper, J. Eng. Gas Turb. Power, 127, 445-451, 2005.

Ha, D. N., Stolarski, T. A., and Yoshimoto, S.: An aerodynamic bearing with adjustable geometry and self-lifting capacity. Part 1: self-lift capacity by squeeze film, International Journal of Engineering Tribology, 219, 33-39, 2005.

Ono, Y., Yoshimoto, S., and Miyatake, M.: Impulse-Load dynamics of squeeze film gas bearings for a linear motion guide, J. Tribol., 131, 1-6, 2009.

Stolarski, T. A.: Numerical modelling and experimental verification of compressible squeeze film pressure, Journal of Tribology International, 43, 356-360, 2009.
Stolarski, T. A. and Chai, W.: Load-carrying capacity generation in squeeze film action, Int. J. Mech. Sci., 48, 736-741, 2006 a.

Stolarski, T. A. and Chai, W.: Self-levitation sliding air contact, Int. J. Mech. Sci., 48, 601-620, 2006b.

Stolarski, T. A. and Woolliscroft, S. P.: Performance of a self-lifting linear air contact, J. Mech. Eng. Sci., 221, 1103-1115, 2007.

Yoshimoto, S., Anno, Y., Sato, Y., and Hamanaka, K.: Floating characteristics of squeeze-film gas bearing with elastic hinges for linear motion guide, International Journal of JSME, 60, 2109 2115, 1995.

Yoshimoto, S., Kobayashi, H., and Miyatake, M.: Floating characteristics of a squeeze - film bearing for a linear motion guide using ultrasonic vibration, Journal of Tribology International, 40, 503-511, 2006.

Wang, C. and Au, Y. H. J.: Levitation Characteristics of a Squeeze Film Air Journal Bearing at its Normal Modes, Journal of Advanced Manufacturing Technology, under revision, 2011.

Zhao, S. and Wallaschek, J.: Design and modelling of a novel squeeze film journal bearing, in: Proceedings of the 2009 IEEE International Conference on Mechatronics and Automation, Changchun, China, 9-12 August 2009, 1054-1059, 2009. 